\title{
Pengaruh Dosis Dan Interval Pupuk Pelengkap Cair Terhadap Daya Hasil Tanaman Padi (Oryza Sativa. L) Model Jajar Legowo
}

\author{
Luluk Sulistiyo Budi ${ }^{*}$, Sri Rahayu*, dan Ma'ruf Pambudi Nurwantara\# \\ \# Fakultas Pertanian, Universitas Merdeka Madiun, Jl. Serayu No 79 Madiun, 63133 \\ E-mail: luluksb@unmer-madiun.ac.id
}

\begin{abstract}
Food needs in the form of rice in Indonesia are still a large component, the population continues to increase, so efforts to increase rice production can also be done well. The research objective is to produce plants optimally and specific targets needed. The research method used a factorial randomized block design using two factors. The first factor is the POC dose with 4 levels namely 0 $\mathrm{cc} / \mathrm{l}, 1 \mathrm{cc} / \mathrm{l}, 1.5 \mathrm{cc} / \mathrm{l}$, and $2 \mathrm{cc} / \mathrm{l}$ and the second factor is the interval of giving 4 days, 6 days once and 8 times a day. The parameters of the observations included plant height, leaf area, number of tillers, panicle number, panicle length, number of grains, the weight of wet stover, dry weight of stover, the weight of dry paddy grain and weight of dry milled rice. Analisa results using Duncan's double test with a $0.5 \%$ royal hose. The results obtained by the combination of POC interval and dose intervals were interaction and gave a significant effect on the rice crop production of the Jowo Legowo model on all observed parameters. The combination of a 4-day time interval with a powerful dose of $1.5 \mathrm{cc} / \mathrm{liter}$ of air, although it cannot be used with $2.00 \mathrm{cc} /$ liter, with milled dry grain production of 8.96 tons/ha.
\end{abstract}

Keywords - : Pupuk Cair; Dosis; Interval jajar legowo.

\section{PENDAHULUAN}

Sistem pertanian yang dilakukan petani sebelum era revolusi hijau merupakan sistem pertanian tradisional. Petani bercocok tanam secara alami tanpa menggunakan pupuk dan pestisida kimia. Seiring dengan laju pertambahan penduduk yang berdampak pada peningkatan kebutuhan pangan, menyebabkan sistem pertanian tradisional bergeser ke sistem pertanian konvensional $\mathrm{Hal}$ ini dikarenakan produksi tanaman dari hasil teknik bercocok tanam tradisional dianggap kurang optimal. Pengelolaan sistem pertanian konvensional memerlukan penggunaan input luar (pupuk dan pestisida kimia) yang lebih banyak. Hal ini disebabkan pola pikir bahwa keadaan lahan dengan tingkat kesuburan tinggi dapat mendukung tercapainya produksi pertanian yang tinggi pula sehingga pemakaian pupuk kimia dilakukan secara berlebih dan terus menerus. Pada awalnya sistem pertanian ini sangat luar biasa dengan produksi pertanian yang tinggi. Hal ini ditunjukkan dengan kemampuan peningkatan pertumbuhan ekonomi secara global, khususnya di bidang pertanian. Terbukti pada keberhasilan pemenuhan kebutuhan hasil-hasil pertanian dalam jangka waktu pendek, sebagai contoh kemampuan Indonesia berswasembada beras pada tahun 1983-1997 (Budi \& Nurwantara, 2017).

Penggunaan pupuk kimia berlebih dalam jangka waktu lama yang diharapkan mampu meningkatkan kesuburan tanah justru sebaliknya yaitu menjadi penyebab menurunnya kualitas tanah. Tanah menjadi keras dan keseimbangan unsur hara dalam tanah terganggu, seperti yang dikemukakan Schaller bahwa terdapat beberapa dampak negatif dari pengelolaan sistem pertanian konvensional antara lain (a) penurunan daya produktivitas lahan karena menurunnya kandungan bahan organik yang menyebabkan produksi semakin menurun (b) penurunan keanekaragaman hayati (flora dan fauna) yang sangat diperlukan pada sistem pertanian berkelanjutan (sustainable agriculture) (c) ketergantungan terhadap sumber daya alam tidak terbarui semakin kuat

Adanya tuntutan untuk menghasilkan produksi pertanian yang tinggi, selain pemakaian pupuk yang berlebih juga menyebabkan intensitas penggunaan lahan sesering mungkin tanpa mengistirahatkan lahan (bera). Hal ini akan mengakibatkan pengurasan unsur hara tanah. Selain penggunaan pupuk kimia dan intensitas pertanaman yang tinggi serta tidak adanya pengembalian bahan organik ke tanah.mengakibatkan keseimbangan unsur hara terganggu.

Kebutuhan akan pangan di suatu negara adalah sangat mutlak. Hal ini sangat berkaitan erat dengan stabilitas keamanan, ketentraman suatu negara. Bahan pangan di Indonesia sangat didominasi oleh pangan utama beras, maka pemerintah berupaya untuk menyiapkan segala upaya agar produksi padi dapat meningkat, bahkan dapat mencapai swasembada beras. Telah banyak upaya yang dilakukan guna peningkatan produksi padi mulai dari pemilihan bibit yang bersertifikat, penggunaan pupuk yang berimbang, model dan teknik pengolahan tanah, model pengairan dan pengendalian hama dan penyakit. Namun demikian masingmasing upaya tersebut tentunya sangat dipengaruhi oleh faktor lingkungan yaitu tempat dimana tanaman padi tersebut di budidayakan, oleh karenanya penerapan teknologi antar wilayah sangatlah berbeda.

Kenyataan dilapang menunjukkan bahwa produktifitas lahan sawah rata-rata 6,55 ton/Ha (BPS 2015) sehingga masih sangat memerlukan sentuhan teknologi yaitu melakukan pola intensifikasi baik penggunaan benih yang unggul, formulasi pemupukan, pengolahan tanah dan atau pengendalian hama dan penyakit. Disamping itu model tanam atau sistem tanam juga akan berpengaruh baik terhadap kelangsungan lingkungan dan produksi. Salah satu model sistem tanam adalah menggunakan jajar legowo. Sistem tanam legowo merupakan cara tanam padi sawah dengan pola beberapa barisan tanaman yang di selingi satu barisan kosong. Tanaman yang seharusnya ditanam pada 
Website : http://agritek.unmermadiun.ac.id/index.php/agritek

barisan yang kosong dipindahkan sebagai tanaman sisipan di dalam barisan. Rekayasa teknik tanam padi dengan cara tanam Jajar Legowo 2:1 atau 4:1. Berdasarkan hasil penelitian terbukti dapat meningkatkan produksi padi sebesar 12-22\% (Bobihoe, 2013). Sistem tanam jajar legowo untuk padi sawah secara umum bisa dilakukan dengan berbagai tipe yaitu: legowo (2:1), (3:1), (4:1), (5:1), (6:1) atau tipe lainnya. Namun dari hasil penelitian (Badan Litbang Pertanian, 2007) Legowo 4:1 menghasilkan produksi gabah tertinggi, tetapi untuk mendapat bulir gabah berkualitas benih lebih baik jika digunakan legowo 2:1. Legowo 2:1 mampu mengurangi kehampaan akibat efek tanaman pinggir. Hasil penelitian Abdulrachman et al (2011) menunjukkan bahwa pada pertanaman Legowo 2:1 dengan jarak tanam $(25 \times 12,5 \times 50) \mathrm{cm}$ mampu meningkatkan hasil antara 9,63-15,44\% dibanding model tegel.

Namun demikian model ini menuai kendala yang yang tidak sedikit yaitu terdapatnya tanaman pengganggu (gulma) yang tinggi, oleh karenannya diperlukan upaya yang tepat terhadap aplikasi pemupukan melalui daun yang dapat mengurangi kehilangan akibat persaingan dengan gulma. Keuntungan pemberian pupuk pelengkap cair ini dilakukan pada bagian bawah daun tanaman secara halus dan pupuk diharapkan tidak sampai jatuh ke permukaan tanah. Aplikasi yang tepat baik cara dan waktunya dapat meningkatkan efisiensi dalam pemberian pupuk. Oleh karenanya sangat diperlukan pengaturan aplikasi baik dosis maupun interval pemberiannya.

Adapun penelitian ini bertujuan unruk mengetahui pengaruh dosis dan interval pemberian pupuk pelengkap cair pada budidaya padi model jajar legowo dan mendapatkan rekomendasi kombinasi perlakuan yang terbaik.

\section{METODE PENELITIAN}

\section{A. Tempat dan Waktu}

Penelitian dilaksanakan di lahan sawah teknis kelurahan Banjarejo Taman Madiun Pada Bulan SeptemberDesember 2018. Adapun uraian jadwal pelaksanaan penelitian dapat dilihat pada Tabel 1 .

\section{B. Bahan dan Alat}

Bahan yang digunakan dalam penelitian meliputi Benih padi Genotip Merdeka, pupuk UREA, Pupuk SP 36 dan KCL, Pupuk Organik, Pupuk Pelengkap Cair Supertani, Insektisida dan Herbisida. Adapun alat yang digunakan hand traktor, cangkul, Sabit, Treser, Terpal, Kertas label dan koran, karung, Tali, mistar, timbangan, dan oven.

Tabel 1

Jadwal Kegiatan

\begin{tabular}{|c|c|c|c|c|c|}
\hline \multirow{2}{*}{ No } & \multirow{2}{*}{ Uraian kegiatan } & \multicolumn{4}{|c|}{ Bulan } \\
\hline & & 2 & 3 & 4 & 5 \\
\hline 1 & Persiapan & & & & \\
\hline 2 & Persemaian & & & & \\
\hline 3 & Pengolahan tanah & & & & \\
\hline 4 & Penanaman & & & & \\
\hline 5 & Pemupukan dasar & & & & \\
\hline 6 & Perlakuan POC & & & & \\
\hline 7 & Pengamatan & & & & \\
\hline 8 & Panen & & & & \\
\hline 9 & Analisa data & & & & \\
\hline
\end{tabular}

10 Pembuatan Jurnal

11 Pembuatan Laporan Akhir

\section{Metode Penelitian}

Penelitian menggunakan rancangan acak kelompok faktorial yaitu Dosis PPC $(0,1 \mathrm{cc} / \mathrm{l}, 1, \mathrm{cc} / \mathrm{l}, 1,5 \mathrm{cc} / \mathrm{l}$ dan $2 \mathrm{cc} / \mathrm{l})$ dan interval pemberian (4 hari sekali, 6 Hari sekali dan 8 hari sekali). Model penanaman dengan Jajar legowo 2:1. Parameter pengamatan di lakukan pada parameter pertumbuhan (tinggi tanaman, jumlah anakan, jumlah anakan produktif, luas daun, berat basah brangkasan, berat kering brangkasan, bobot 1000 butir gabah, berat kering sawah dan berat kering giling. Analisis dilakukan dengan uji statistik perbandingan ganda Duncan 0,5\%.

\section{Pelaksanaan Penelitian}

Pelaksanaan penelitian dilakukan meliputi tahapantahapan kegiatan yaitu pembuatan persemaian seluas $10 \%$ dari luas areal penelitian

- Persiapan lahan dengan membersihkan sisa-sisa tanaman sebelumnya agar tidak mengganggu proses pengerjaan lahan dan lahan di airi/diberi air.

- Menambahkan pupuk organik/bokasi sesuai rekomendasi 3 ton/ha secara merata.

- Pengolahan lahan/tanah dilakukan menggunakan hand traktor dengan alat singkal dan garu sisir agar rata

- Setelah pengolahan tanah lahan digenangi sampai 7 hari agar biji-biji gulma tidak tumbuh serta lahan lebih berlumpur dan lebih baik untuk media tumbuh.

- Sementara itu melakukan perawatan pada persemaian agar bebas dari serangga hama dengan pengendalian terpadu.

- Persiapan penanaman dimulai dengan Mencabut bibit pada dari persemaian yang telah berumur 17 hari.

- Penanaman dilakukan dengan model jajar legowo 2:1.

- Melakukan pemupukan pertama dengan NPK yang 0,5 dari rekomendasi yaitu Urea $200 \mathrm{~kg} / \mathrm{Ha}$, SP 3615 kg/Ha dan KCL 100 kg/Ha (Budi \& Nurwantara, 2017).

- Pemupukan diberikan dalam baris antar tanaman untuk jajar legowo.

- Penyiangan gulma sekaligus membuat parit-parit antar baris tanaman dan pengendalian hama terpadu.

- Melakukan pengamatan secara periodik terhadap parameter pertumbuhan dan produksi, pengamatan dilakukan setiap 10 hari sekali.

- Pengamatan pertumbuhan dilakukan menggunakaninstrumen yang telah di tentukan sebelumnya.

- Parameter tinggi tanaman diukur mulai atas tanah sampai dengan ujung daun bendera.

- Parameter jumlah anakan dihitung jumlah anakan seluruhnya

- Parameter jumlah anakan produktif dihitung pada semua anakan yang keluar malai.

- Panen dilakukan setelah tanaman tua ditandai dengan bulir menguning mencapai $80 \%$.

Pengamatan parameter produksi dilakukan pada saat panen meliputi jumlah anakan produktif, berat basah brangkasan, berat kering brangkasan, prosentase gabah berisi, 
Website : http://agritek.unmermadiun.ac.id/index.php/agritek

dan prosentase gabah hampa. Jumlah butir permalai, berat kering sawah dan berat kering giling.

\section{HASIL DAN PEMBAHASAN}

Hasil analisis menunjukkan bahwa pengaruh interfal pemberian dan dosis POC pada tanaman padi model jajar lehowo menunjukkan adanya interaksi terhadap semua parameter pangamatan tinggi tanaman, jumlah anakan, jumlah malai, berat basah brangkasan, berat kering brangkasan, jumlah butir permalai, berat gabah kering sawah dan berat gabah kering giling/produksi per Ha (lampiran1). Nilai rata-rata hasil pengamatan disajikan pada Tabel 1 dan 2.

Tabel 1.

Nilai rata-rata hasil pengamatan pengaruh kombinasi perlakuan antara interval pemberian dan dosis POC terhadap parameter pertumbuhan pada tanaman padi model jajar legowo.

\begin{tabular}{|c|c|c|c|c|c|c|}
\hline perlakuan & Tingg Tanaman & $\begin{array}{l}\text { Jumlah } \\
\text { Anakan }\end{array}$ & Jumlah Małai & Luas Daun & $\begin{array}{l}\text { Berat } \\
\text { Basah } \\
\text { Brangla }\end{array}$ & $\begin{array}{c}\text { Berat } \\
\text { Kering } \\
\text { Brangkasan }\end{array}$ \\
\hline P1DO & $112.60 \mathrm{a}$ & $8.00 \mathrm{a}$ & $8.00 \mathrm{a}$ & 1698 a & $16.66 \mathrm{a}$ & $8.33 a$ \\
\hline P1D1 & $12080 \mathrm{ab}$ & $13.40 \mathrm{~b}$ & $13.40 \mathrm{~b}$ & $24.68 \mathrm{ab}$ & 25.20 at & $12.60 \mathrm{ab}$ \\
\hline PID2 & $120.00 \mathrm{ab}$ & $1280 \mathrm{~b}$ & $12.80 \mathrm{~b}$ & $28.89 \mathrm{ab}$ & $3236 \mathrm{~b}$ & $16.18 \mathrm{~b}$ \\
\hline P1D3 & $127.50 \mathrm{~b}$ & $12.00 \mathrm{~b}$ & $11.60 \mathrm{ab}$ & $34.16 \mathrm{ab}$ & 23.26 at & $11.63 a b$ \\
\hline$P 200$ & $120.00 \mathrm{ab}$ & $12.60 \mathrm{~b}$ & $12.20 \mathrm{~b}$ & $22.62 \mathrm{ab}$ & $32.86 \mathrm{~b}$ & $16.04 \mathrm{~b}$ \\
\hline P2D1 & $120.80 a b$ & $1320 \mathrm{~b}$ & $12.80 \mathrm{~b}$ & $31.48 \mathrm{~b}$ & $3390 \mathrm{~b}$ & $16.38 \mathrm{~b}$ \\
\hline P2D2 & $118.40 \mathrm{ab}$ & $1320 \mathrm{~b}$ & $13.20 \mathrm{~b}$ & $3398 \mathrm{~b}$ & $33.76 \mathrm{~b}$ & $16.88 \mathrm{~b}$ \\
\hline P2D3 & $11990 \mathrm{ab}$ & $11.60 \mathrm{~b}$ & $11.60 \mathrm{ab}$ & $30.81 a b$ & 25.18 at & $12.59 \mathrm{ab}$ \\
\hline PBDO & $121.90 \mathrm{ab}$ & $12.40 \mathrm{~b}$ & $11.80 \mathrm{~b}$ & $23.50 \mathrm{ab}$ & $32.98 \mathrm{~b}$ & $15.82 \mathrm{~b}$ \\
\hline P3D1 & $12090 \mathrm{ab}$ & $12.40 \mathrm{~b}$ & $11.60 \mathrm{ab}$ & $2195 \mathrm{ab}$ & $29.00 \mathrm{~b}$ & $14.50 \mathrm{~b}$ \\
\hline P3D2 & $117.80 \mathrm{ab}$ & $12.20 \mathrm{~b}$ & $12.00 \mathrm{~b}$ & $18.78 \mathrm{a}$ & $30.40 \mathrm{~b}$ & $15.20 \mathrm{~b}$ \\
\hline P2D3 & $121.40 \mathrm{ab}$ & $1180 \mathrm{~b}$ & $11.80 \mathrm{~b}$ & $17.88 \mathrm{ab}$ & $29.02 \mathrm{~b}$ & $14.51 \mathrm{~b}$ \\
\hline
\end{tabular}

Keterangan: Angka-angka yang didampingi huruf yang sama menunjukkan tidak berbeda nyata dengan uji Duncan $0,05 \%$

Tabel 2.

Nilai rata-rata hasil pengamatan pengaruh kombinasi perlakuan antara interval pemberian dan dosis POC terhadap parameter produksi pada tanaman padi model jajar legowo.

\begin{tabular}{crrrrr}
\hline Perlakuan & $\begin{array}{c}\text { Jumlah } \\
\text { biji/malai }\end{array}$ & $\begin{array}{c}\text { Berat kering } \\
\text { sawah }\end{array}$ & $\begin{array}{c}\text { Berat kering } \\
\text { Giling }\end{array}$ \\
\hline P1D0 & 95.80 & a & 5.69 & a & 5.20 a \\
P1D1 & 152.80 abc & 7.29 & ab & 6.80 ab \\
PID2 & 172.40 c & 9.26 & b & 8.77 b \\
P1D3 & 101.40 ab & 9.26 & $\mathbf{b}$ & 8.96 b \\
P2D0 & 141.00 abc & 8.62 & $\mathbf{b}$ & 7.04 b \\
P2D1 & 122.20 abc & 8.67 & $\mathbf{b}$ & 7.90 b \\
P2D2 & 137.80 abc & 9.25 & $\mathbf{b}$ & 8.36 b \\
P2D3 & 136.60 abc & 8.19 & ab & 7.70 ab \\
P3D0 & 146.80 abc & 7.93 & ab & 7.44 ab \\
P3D1 & 117.00 abc & 7.64 & ab & 7.15 ab \\
P3D2 & 126.60 abc & 7.54 & ab & 7.05 ab \\
P2D3 & 154.60 bc & 8.09 & ab & 7.60 ab \\
\hline
\end{tabular}

Keterangan: Angka-angka yang didampingi huruf yang sama menunjukkan tidak berbeda nyata dengan uji Duncan $0,05 \%$

Sebagaimana disajikan pada tabel 1 bahwa semua perlakuan menunjukkan adanya interaksi yang nyata dimana masing-masing perlakuan menunjukkan interaksi yang berbeda sebagaimana disajikan pada gambar 1-9 berikut:

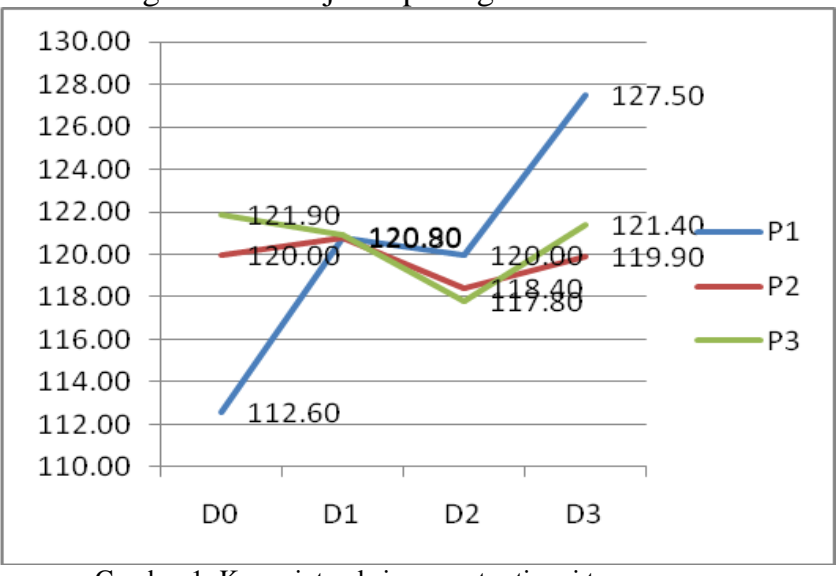

Gambar 1. Kurva interaksi parameter tinggi tanaman

Terlihat pada Gambar1 bahwa nilai rata-rata tinggi tanaman tertinggi di capai kombinasi perlakuan interval pemberian dan dosis PPC 4 hari sekali dengan dosis 2 cc/liter yaitu $127.5 \mathrm{~cm}$, sedangkan terendah dengan pemberian 4 hari sekali dengan dosis PPC 0cc/liter. Yaitu $112,60 \mathrm{~cm}$.

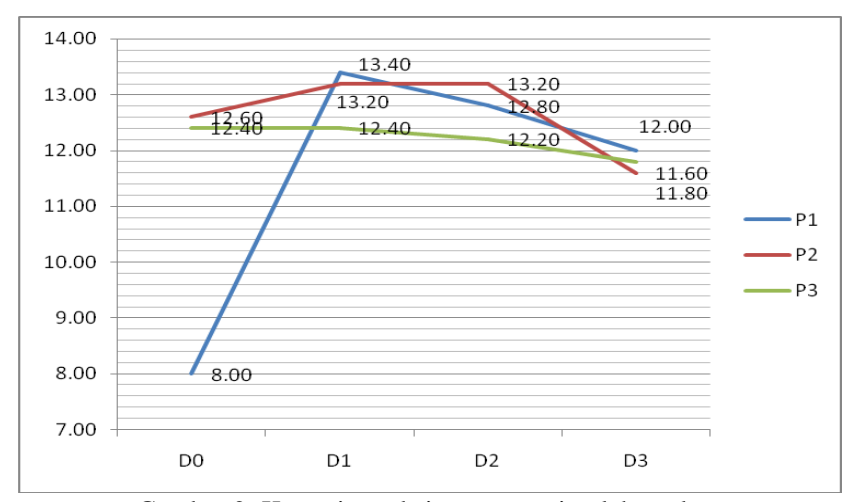

Gambar 2. Kurva interaksi parameter jumlah anakan

Terlihat pada Gambar 2. bahwa nilai rata-rata jumlah anakan tertinggi di capai kombinasi perlakuan interval pemberian dan dosis PPC 6 hari sekali dengan dosis $1.5 \mathrm{cc} /$ liter yaitu 13.4 , sedangkan terendah dengan pemberian 4 hari sekali dengan dosis PPC 0cc/liter. Yaitu 8.

Terlihat pada Gambar 3. bahwa nilai rata-rata jumlah malai tertinggi di capai kombinasi perlakuan interval pemberian dan dosis PPC 4 hari sekali dengan dosis $1.0 \mathrm{cc} /$ liter yaitu 13.4 , sedangkan terendah dengan pemberian 4 hari sekali dengan dosis PPC 0cc/liter. Yaitu 8.

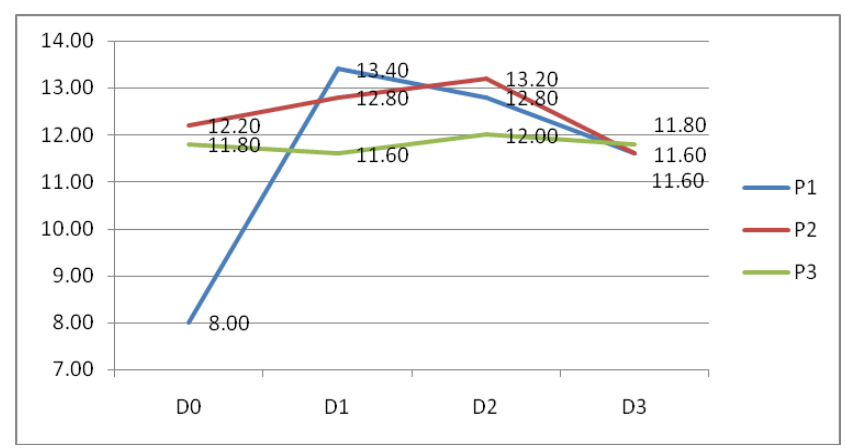

Gambar 3. Kurva interaksi parameter jumlah malai 
Website : http://agritek.unmermadiun.ac.id/index.php/agritek

pemberian dan dosis PPC 6 hari sekali dengan dosis $1.5 \mathrm{cc} /$ liter yaitu $16,88 \mathrm{~g}$, sedangkan terendah dengan pemberian 4 hari sekali dengan dosis PPC 0cc/liter. Yaitu $8,33 \mathrm{~g}$.

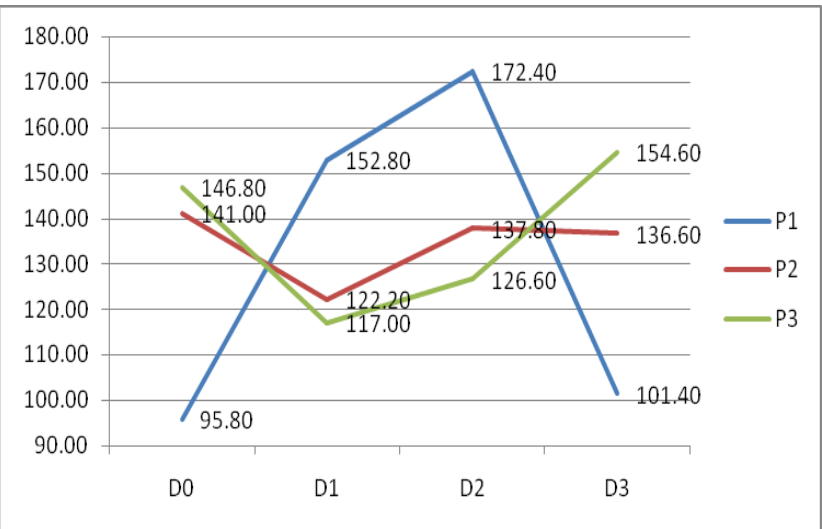

Gambar 4. Kurva interaksi parameter jumlah biji permalai

Terlihat pada Gambar 4. bahwa nilai rata-rata jumlah biji permalai tertinggi di capai kombinasi perlakuan interval pemberian dan dosis PPC 4 hari sekali dengan dosis $1.5 \mathrm{cc} /$ liter yaitu 172,4 , sedangkan terendah dengan pemberian 4 hari sekali dengan dosis PPC 0cc/liter yaitu 95,8 .

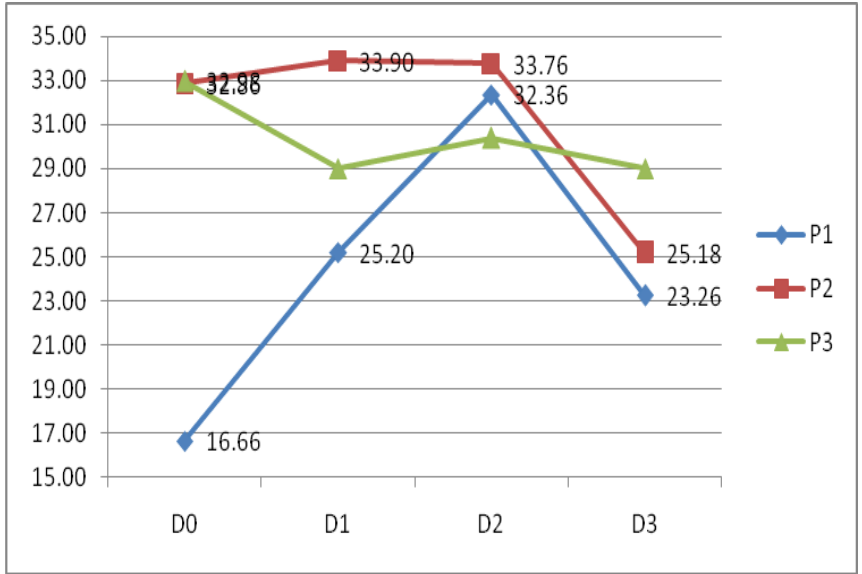

Gambar 5. Kurva interaksi parameter berat basah brangkasan

Terlihat pada Gambar 5. bahwa nilai rata-rata berat basah brangkasan tertinggi di capai kombinasi perlakuan interval pemberian dan dosis PPC 6 hari sekali dengan dosis 1.0 cc/liter yaitu 33,99 g, sedangkan terendah dengan pemberian 4 hari sekali dengan dosis PPC 0cc/liter. Yaitu 16,66 g.

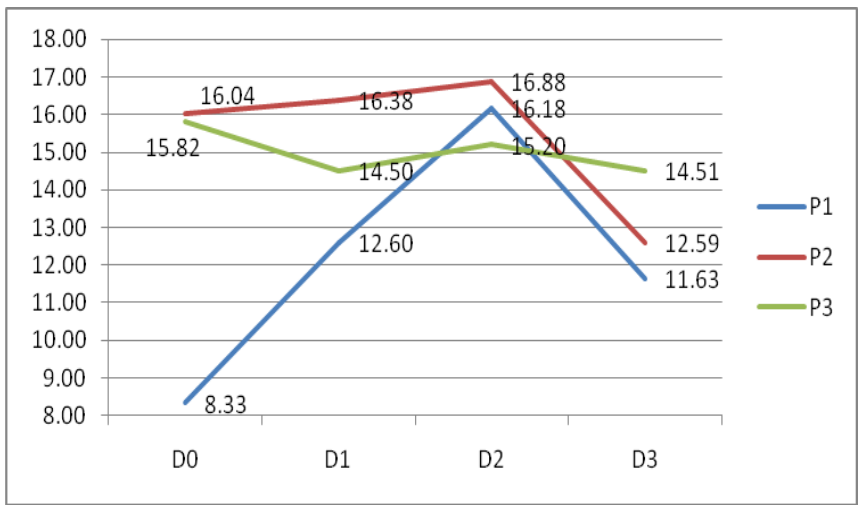

Gambar 6. Kurva interaksi parameter berat kering brangkasan

Terlihat pada Gambar 6. bahwa nilai rata-rata berat kering brangkasan tertinggi di capai kombinasi perlakuan interval

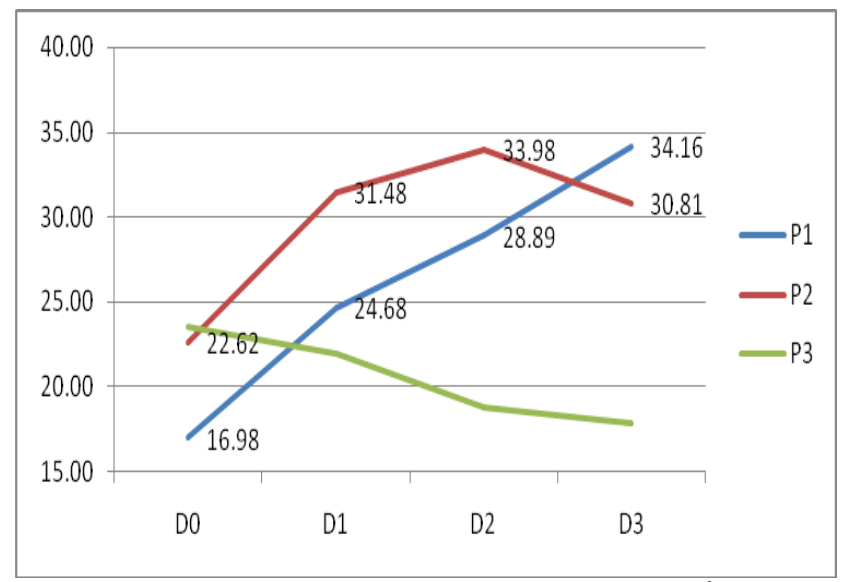

Gambar 7 . Kurva interaksi parameter luas daun $\left(\mathrm{cm}^{2}\right)$

Terlihat pada Gambar 7. bahwa nilai rata-rata luas daun tertinggi di capai kombinasi perlakuan interval pemberian dan dosis PPC 4 hari sekali dengan dosis 2,0cc/liter yaitu $34,16 \mathrm{~cm}^{2}$, sedangkan terendah dengan pemberian 4 hari sekali dengan dosis PPC 0cc/liter. Yaitu $16,98 \mathrm{~cm}^{2}$.

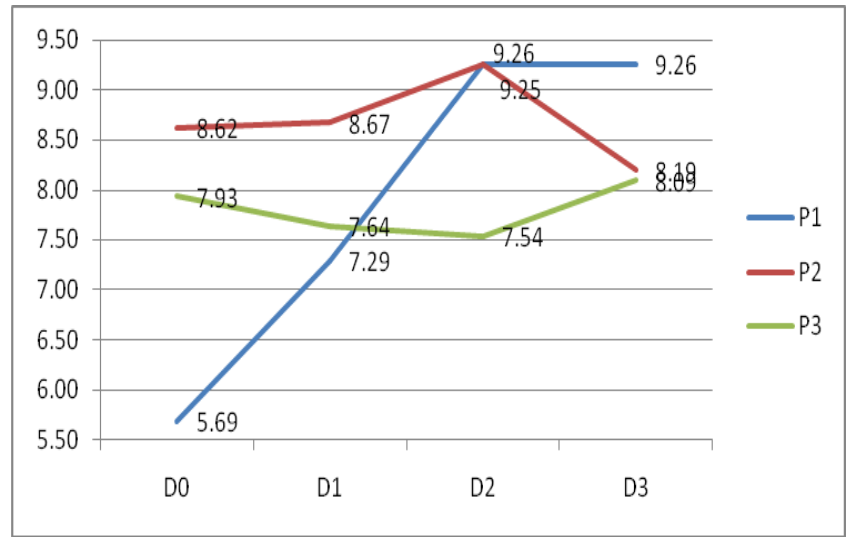

Gambar 8 . Kurva interaksi parameter berat gabah kering sawah

Terlihat pada Gambar 8. bahwa nilai rata-rata berat gabah kering sawah tertinggi di capai kombinasi perlakuan interval pemberian dan dosis PPC 4 hari sekali dengan dosis $1.5 \mathrm{cc} /$ liter yaitu $9,26 \mathrm{~g}$, sedangkan terendah dengan pemberian 4 hari sekali dengan dosis PPC 0cc/liter. Yaitu $5,69 \mathrm{~g}$.

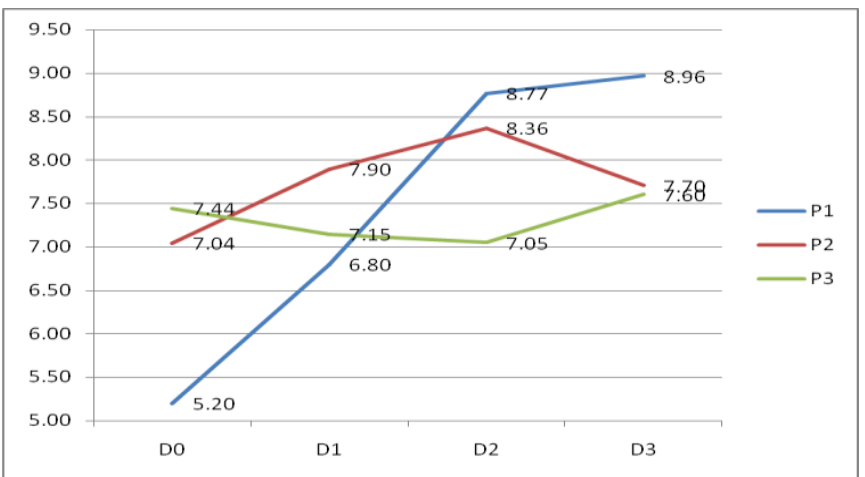

Gambar 9 . Kurva interaksi parameter berat gabah kering giling 
Terlihat pada Gambar 9. bahwa nilai rata-rata berat gabah kering giling tertinggi di capai kombinasi perlakuan interval pemberian dan dosis PPC 4 hari sekali dengan dosis 2,0cc/liter yaitu 8,96 Ton, sedangkan terendah dengan pemberian 4 hari sekali dengan dosis PPC 0cc/liter. Yaitu 5,20 Ton.

Selanjutnya hasil analisis terhadap hubungan antar parameter dapat dijelaskan dalam tabel 3. Terlihat pada Tabel 3. bahwa terdapat hubungan yang positif antara parameter tinggi tanaman dengan jumlah anakan, berat basah brangkasan, berat kering brangkasan, berat gabah kering sawah, dan berat gabah kering giling. Korelasi sangat kuat antara jumlah anakan dengan jumlah malai yaitu mencapai nilai 0.984, juga diikuti korelasi yang kuat terhadap berat basah brangkasan, berat kering brangkasan, berat gabah kering sawah dan berat gabah kering giling.
Tabel 3 menunjukkan korelasi antar parameter pertumbuhan tanaman. Parameter tinggi tanaman memiliki korelasi dengan parameter jumlah anakan, berat basah brangkasan, berat kering brangkasan, berat kering sawah, dan berat kering giling. Parameter jumlah malai memiliki korelasi dengan parameter jumlah anakan, berat basah brangkasan, berat kering brangkasan, berat kering sawah, dan berat kering giling.

Parameter jumlah anakan memiliki korelasi dengan parameter berat basah brangkasan, berat kering brangkasan, berat kering sawah, dan berat kering giling. Parameter jumlah butir malai 1 tidak memiliki korelasi dengan parameter lainnya. Parameter berat basah brangkasan memiliki korelasi dengan parameter berat kering brangkasan, berat kering sawah, dan berat kering giling.

Tabel 3.

Correlations

\begin{tabular}{|c|c|c|c|c|c|c|c|c|c|c|}
\hline & & $\mathbf{T T}$ & $\mathbf{J M}$ & JA & JBM & BBB & BKB & BKS & BKG & LD \\
\hline \multirow[t]{2}{*}{ TT } & Pearson Correlation & $\mathbf{1}$ & .244 & $.267 *$ & .181 & $.370^{* * *}$ & $.370^{* * *}$ & $359 * *$ & $360^{* * *}$ & .113 \\
\hline & $\mathbf{N}$ & 60 & 60 & 60 & 60 & 60 & 60 & 60 & 60 & 60 \\
\hline \multirow[t]{3}{*}{$\mathbf{J M}$} & Pearson Correlation & .244 & $\mathbf{1}$ & $.984 * *$ & .191 & $.834 * *$ & $.834 * *$ & $800 * *$ & $800 * *$ & .109 \\
\hline & Sig. (2-tailed) & .060 & & .000 & .145 & .000 & .000 & .000 & .000 & .408 \\
\hline & $\mathbf{N}$ & 60 & 60 & 60 & 60 & 60 & 60 & 60 & 60 & 60 \\
\hline \multirow[t]{3}{*}{ JA } & Pearson Correlation & $.267 *$ & $.984^{* * *}$ & 1 & .162 & $.844^{* * *}$ & $.844^{* * * k}$ & $.790^{* * *}$ & $.790^{* * * k}$ & .153 \\
\hline & Sig. (2-tailed) & .040 & .000 & & .217 & .000 & .000 & .000 & .000 & .243 \\
\hline & $\mathrm{N}$ & 60 & 60 & 60 & 60 & 60 & 60 & 60 & 60 & 60 \\
\hline \multirow[t]{3}{*}{ JBM } & Pearson Correlation & .181 & .191 & .162 & 1 & .237 & .237 & .214 & .214 & -.122 \\
\hline & Sig. (2-tailed) & .167 & .145 & .217 & & .069 & .069 & .100 & .100 & .355 \\
\hline & $\mathrm{N}$ & 60 & 60 & 60 & 60 & 60 & 60 & 60 & 60 & 60 \\
\hline \multirow[t]{3}{*}{ BBB } & Pearson Correlation & $.370^{* * *}$ & $.834^{* * *}$ & .844 ** & .237 & 1 & $1.000^{* * *}$ & $.815^{* * *}$ & $.815^{* * *}$ & .128 \\
\hline & Sig. (2-tailed) & .004 & .000 & .000 & .069 & & .000 & .000 & .000 & .330 \\
\hline & $\mathrm{N}$ & 60 & 60 & 60 & 60 & 60 & 60 & 60 & 60 & 60 \\
\hline \multirow[t]{3}{*}{ BKB } & Pearson Correlation & $.370^{* * *}$ & $.834^{\text {*w* }}$ & .844 * * * & .237 & $1.000^{* * *}$ & 1 & $.815^{* *}$ & $.815^{* * *}$ & .128 \\
\hline & Sig. (2-tailed) & .004 & .000 & .000 & .069 & .000 & & .000 & .000 & .330 \\
\hline & $\mathbf{N}$ & 60 & 60 & 60 & 60 & 60 & 60 & 60 & 60 & 60 \\
\hline BKS & $\mathbf{N}$ & 60 & 60 & 60 & 60 & 60 & 60 & 60 & 60 & 60 \\
\hline \multirow[t]{3}{*}{ B KG } & Pearson Correlation & $.360^{* * *}$ & $.800^{* * * *}$ & .790 ** & .214 & $.815^{* * *}$ & .815 *** & $1.000^{\text {*2* }}$ & 1 & .145 \\
\hline & Sig. (2-tailed) & .005 & .000 & .000 & .100 & .000 & .000 & .000 & & .269 \\
\hline & $\mathrm{N}$ & 60 & 60 & 60 & 60 & 60 & 60 & 60 & 60 & 60 \\
\hline \multirow[t]{3}{*}{ LD } & Pearson Correlation & .113 & .109 & .153 & -.122 & .128 & .128 & .145 & .145 & 1 \\
\hline & Sig. (2-tailed) & .390 & .408 & .243 & .355 & .330 & .330 & .270 & .269 & \\
\hline & $\mathbf{N}$ & 60 & 60 & 60 & 60 & 60 & 60 & 60 & 60 & 60 \\
\hline
\end{tabular}


Website : http://agritek.unmermadiun.ac.id/index.php/agritek

Parameter berat kering brangkasan memiliki korelasi dengan parameter berat kering sawah, dan berat kering giling. Parameter berat kering sawah memiliki korelasi dengan berat kering giling. Parameter berat kering giling tidak memiliki korelasi dengan parameter lebar daun. Parameter lebar daun tidak memiliki korelasi dengan parameter lainnya.

Adanya korelasi antara setiap parameter dapat dilihat dari ada tidaknya tanda bintang $(* / * *)$ pada nilai pearson correlation. Nilai pearson correlation yang memiliki tanda bintang $(* / * *)$ menandakan bahwa kedua parameter tersebut memiliki korelasi, sedangkan jika tidak ada tanda bintang $(* / * *)$ maka kedua parameter tersebut tidak memiliki korelasi.

Selain itu nilai signifikansi juga dapat menunjukkan ada atau tidaknya korelasi antar dua parameter. Nilai signifikansi yang berada di bawah 0,05 ( $\mathrm{sig}<0,05$ ) menunjukkan bahwa kedua parameter memiliki korelasi. Nilai signifikasi yang berada di atas 0,05 ( $\mathrm{sig}>0,05)$ menunjukkan bahwa kedua parameter tidak memiliki korelasi.

Dalam bentuk data merupakan bagian yang disajikan untuk menginformasikan hasil temuan dari penelitian yang telah dilakukan. Ilustrasi hasil penelitian dapat menggunakan grafik/tabel/gambar. Sedangkan pembahasan mengemukakan keterkaitan antar hasil penelitian dengan teori, perbandingan hasil penelitian dengan $h$

Hasil penelitian lain yang sudah dipublikasikan. Pembahasan menjelaskan pula implikasi temuan yang diperoleh bagi ilmu pengetahuan dan pemanfaatannya.

\section{KESIMPULAN}

\section{A. Kesimpulan}

Berdasarkan hasil analisis dapat ditarik kesimpulan menunjukkan bahwa:

1. Perlakuan kombinasi perlakuan antara interval pemberian dan dosis POC terdapat interaksi yang nyata pada semua parameter.

2. Kombinasi perlakuan terbaik adalah interval pemberian 4 hari sekali dengan dosis POC 1,5 cc/liter, meskipun tidak berbeda nyata dengan dosis POC 2,0 cc/liter.

B. Saran

Perlu dilakukan kajian lanjutan terhadap beberapa varietas tanaman padi dan penggunaan pupuk cair alami lainnya.

\section{UCAPAN TERIMAKASIH}

Ucapan terima kasih disampaikan kepada Rektor Universitas Merdeka Madiun, Cq. Ketua Lembaga Penelitian dan Pengabdian Kepada Masyarakat, dan Dekan Fakultas Pertanian Universitas Merdeka Madiun

\section{VI.DAFTAR PUSTAKA}

Arifin, M., Ariani, K. T., \& Haelitik, S. A. (2017). Diskripsi Sikap Petani dalam Penerapan sistem tanam jajar legowo pada padi sawah. Agrica Ekstensia volume 11.1, 22-31.

Budi, L. S., \& Nurwantara, M. P. (2017). Uji Daya Hasil Tanaman Padi (Oryza Sativa. L) Model Jajar Legowo Di Kota Madiun. Agri-Tek , 1-7.

Misran. (2014). Studi Sistem Tanam Jajar Legowo Terhadap Produktivitas Padi Sawah. Jurnal Penelitian Pertanian Terapan , 14 (2), 106-110.
Nurjanah, S. (2015, Agustus Senin). Jajar Legowo sebagai Pengungkit Swasembada Padi. Tabloit Sinar Tani , pp. 2-6.

Satria, B., Harahap, E. M., \& Jamilah. (2017). Peningkatan Produktivitas Padi Sawah (Oryza sativa L.) Melalui Penerapan Beberapa Jarak Tanam dan sistem Tanam. jurnal Agroteknologi FP USU , 5 (3), 629 637.

Sutanto, R. (2002). Pertanian Organik. Yogyakarta: Kanisius.

Sutedjo, M. M. (2010). Pupuk dan Cara Pemupkan. Jakarta: Rineka Cipta. Yulipriyanto, H. (2010). Biologi Tanah dan Strategi Pengelolaannya. Yogyakarta: Graha Ilmu 